\title{
Factors Related to Depressive Complaints on Climacteric: a Cross-Sectional Study \\ ORIGINAL
}

\begin{abstract}
Maria do Carmo Andrade Duarte de Farias ${ }^{1}$, Arthur Brenno Victor dos Santos ${ }^{2}$, Suellen Martins de Oliveira ${ }^{2}$, Tatiana Abrantes Gonçalves ${ }^{2}$, Francisca Bezerra de Oliveira ${ }^{3}$, Sheylla Nadjane Batista Lacerda4, Marilena Maria de Souza ${ }^{3}$, Francisco Fábio Marques da Silva ${ }^{3}$, Betânia Maria Pereira dos Santos ${ }^{3}$, Kennia Sibelly Marques de Abrantes ${ }^{3}$, Anne Milane Formiga Bezerra5, Kévia Katiúscia Santos Bezerra1, Gerlane Cristinne Bertino Veras ${ }^{3}$, Luiz Carlos de Abreu6
\end{abstract}

\section{Abstract}

Introduction: Climacterium is a period of a woman's life, between 35 and 65 years old, marked by hormonal and biopsychosocial changes that can lead to the onset of depressive symptoms. The aim was to identify the prevalence of and factors associated with depressive symptoms in climacteric women.

Method: An exploratory study, of cross-sectional type research, was carried out in Cajazeiras, Paraíba, Brazil, from January 2013 to March 2014. The sample included 411 women aged 40 to 60. Data collection was done by interviews using a structured script. Mean and standard deviation of age variables and per capita income were identified. For correlation between the variables, we used odds ratios $(\mathrm{Cl} 95 \%)$, the $\mathrm{X}^{2}$ and Fisher's Exact Test, with a significance level of $5 \%$.

Results: The average age of women was 49.73 ( \pm 5.799) years. Depressive complaints prevailed in $68.1 \%$, associated with advanced age ( $p=0.009$; OR: 1.693 [Cl 1.113-2.577]), low education ( $p=0.022$; OR: 1.568 [Cl 1.032-2.382]), lower per capita income ( $p=0.043$; OR: 1.553 [Cl 1.012-2.384]), unpaid labor activity ( $p=0.013$; OR: $1.641[\mathrm{Cl}$ 1.079-2.495]), menopausal/postmenopausal ( $p=0.011$; OR: 1.667 [Cl 1.092-2.545]), sexual activity with complaint $(p<0.001$ [OR: 2.777; [Cl 1.628-4.737]) and the presence of at least one disease $(p<0.001$; OR: 2.230 [Cl 1.445-3.440]).

Conclusion: Understanding and addressing the factors related to depressive complaints during climacterium supports the importance of conducting disease prevention programmes, thus delaying the onset of morbidity and improving quality of life.
1 Academic Unit of Life Sciences, Teacher's Training Center, Federal University of Campina Grande, Cajazeiras, Paraíba, Brazil.

2 Bachelor of Medicine, Federal University of Campina Grande, Cajazeiras, Paraíba, Brazil.

3 Academic Unit of Nusing, Teacher's Training Center, Federal University of Campina Grande, Cajazeiras, Paraíba, Brazil.

4 Teacher of Faculty Santa Maria, Cajazeiras, Paraíba, Brazil.

5 Nurse in the Mobile Emergency Service, MSU, Sousa, PB, Brazil.

6 Scientific Writing Laboratories, Faculty of Medicine of $A B C$, Santo Andre, SP, Brazil.

Contact information:

Maria do Carmo Andrade Duarte de Farias.

” carmofarias@hotmail.com

Keywords

Climacterium; Depression; Risk factors; Socioeconomic Factors. 


\section{Introduction}

The ageing of the world's population is one of the notable achievements of medicine, and is also a source of challenges, as physical and cognitive interventions are sought to alleviate the harmful effects of senility. From the biological point of view, changes occur in the cardiorespiratory and neuromuscular systems, and physical and intellectual capacity, with advancing years. In women, these changes are particularly related to menopause.

The main importance of addressing the climacteric in public health is to increase the number of women over 50 years old in the world's population: 467 million in 1990 is expected to reach 1.2 billion in 2030. In Brazil, population senescence expresses a tendency to feminization, since women over 40 years old represent $32 \%$ of the population. [1]

In 2013, the life expectancy of women in Brazil was 78.6 years. [2] So, with menopause established at around 50, women will live around a third of their life after this event, deserving special attention in order to live as healthily as possible. [3]

Menopause is a period of life in which there is a transition from the reproductive to the non-reproductive phase, with the gradual decline of ovarian function, [4] represented by various changes with menopause as apex.

The greater sensitivity to ageing coupled with stress symptoms resulting from ovarian failure, has a direct influence on sexuality and coincides with the onset of chronic pathologies, associated with weight gain; emotional adjustments and lifestyle changes are required, which are sometimes difficult for women, promoting feelings of worthlessness, sadness and depression.

In Brazil, a study revealed that $73.2 \%$ of depressive complaints by menopausal women were reported as melancholy or sadness, according to the Blatt-Kupperman Menopausal Index, one of the tools used in the evaluation of climacteric symptoms. [5]
Hormonal and sociocultural factors and comorbidities may individually or synergistically affect the incidence of depressive symptoms, especially postmenopausally. [6] It is estimated that a third of women will suffer at least one episode of depression during her life, $9 \%$ of which are linked to the climacteric period. [7]

People with depression demand higher spending by the health-care system, [8] have reduced willingness to work and have lower adherence to medical treatments. Among the complications related to depression are social, marital and professional problems, with a consequent decrease in quality of life and, in its severest form, suicide. [7] Therefore, depressive complaints during menopause should not be underestimated or neglected, at risk of becoming worse or fatally compromised.

The objectives were to identify the prevalence of depressive symptoms and factors related to its genesis, in menopausal women attending basic health units in an urban area, a city in Northeast Brazil.

\section{Material and Method}

The study is a cross-sectional survey, conducted between January 2013 and March 2014 in the city of Cajazeiras, a city of the Paraiba backlands; it has a land area of $566 \mathrm{~km}^{2}$ and an estimated population of 58.443 inhabitants. [9]

The sample was calculated probabilistically, adopting a 95\% confidence interval, significance level of $5 \%$ and sample error of $5 \%$, based on the population of 9.966 women, aged 35-65 years old, as reported by the Department of Informatics of the Unified Health System. [9] The womens were recruited by home visits and consultations scheduled for health units of origin.

By calculation, the sample to be investigated was 385 women. A total of 543 women were interviewed. However, when considering the eligibility criteria for participation in the study, women were excluded if they were taking hormone replacement 
therapy (HRT) ( $n=19)$, had had a hysterectomy and were using HRT ( $n=01$ ) or had had a hysterectomy ( $n=19$ ) as these factors interfere with menstrual flow; women aged 35-39 years $(n=54)$ and over 60 ( $n=39)$ were also excluded, as before 40 years climacteric symptoms are virtually absent, and also after 60 through adapting to symptoms and the near absence of complaints. To correlate depressive complaints with Body Mass Index (BMI), those with low weight $(n=8)$ were excluded, considering the reduced frequency which did not allow statistical analysis.

The final sample of 411 women aged 40-60 years who had no prior history of depression (as depression has high relapse rates, [10] refuting doubts about the genesis of depressive complaints) and who agreed to participate after clarification, read and signed the informed consent (IC) in compliance with ethics in human research.

Data collection was done by conducted interview with structured script, carried out in health units. The variables analyzed were: Age in years, family income per capita (both dichotomized the average), occupation, BMI (weight/height ${ }^{2}$ ), menopausal state, sexual activity, presence of comorbidities (self-referred), hypertension and diabetes (identified by registration in a Monitoring System of Hypertensive and Diabets (HIPERDIA) and the use of specific medications and depressive symptoms (associated report of sadness, anxiety, crying spells, discouragement).

Family income per capita was obtained by the sum of family income divided by the number of family members, with reference to the actual minimum wage, effective at the time of data collection.

Occupation was categorized as with income or no income (the household, farmer or fisherman); sexual activity as present or absent, and when present, as with and without complaint; menopausal status as premenopausal (women with maintained regular or irregular menstrual cycle) or postmenopausal (absent menstruation for 12 months or more). To characterize the presence of diseases, there were reports of cancer, hypothyroidism and hyperthyroidism, osteoporosis, cardiovascular disease and diabetes.

The depressive complaints (sadness/grief) variables were addressed when applying the Blatt-Kupperman Menopausal Index (BKMI). This index is used in the diagnosis of climacteric syndrome and ranks symptoms according to mild, moderate and severe intensity, according to the score obtained. [11]

For purposes of correlation between the variables, depressive complaints were categorized as absent or present, regardless of the intensity. Such complaints were identified subjectively by asking whether, in recent days, the interviewee felt sad or melancholic or hedonic most of the time had feelings of guilt or excessive worthlessness, difficulty concentrating, fatigue, sleep disturbances, agitation or psychomotor retardation, significant increase or weight reduction, and recurrent ideas of death and suicide; all of these were identified as depressive symptoms. [12]

The data collection instruments were listed sequentially. Descriptive results were used for the mean and standard deviation of the variables of age, education and per capita income, and the prevalence of lifestyle variables and morbid thoughts, based on the total of 411 women interviewed. To investigate the prevalence and association of the presence of depressive symptoms and correlated variables, odds ratios were used, with a confidence interval of $95 \%$ and $p<0.05$. The Chi-square Test $\left(X^{2}\right)$ and Fisher's Exact Test were also used when necessary to reject the null hypothesis. This association was confirmed by the linear regression model. For the analysis and tabulation of data, the EXCEL program and the Statistical Package for Social Sciences (SPSS) version 22, free to download, was used.

This study is part of a research 'Symptoms of menopause: severity and associated factors' which was approved by the Ethics Committee of the State 


\section{INTERNATIONAL ARCHIVES OF MEDICINE \\ Section: Psychiatry \& Mental Health \\ ISSN: 1755-7682}

Vol. 8 No. 244

doi: $10.3823 / 1843$

University of Paraíba-UEPB, according to the protocol number 0462.0.133.000-11, dated 14/09/2011. The subjects involved were guaranteed clarification at any desired point, and the freedom to refuse to participate in the study, withdraw consent or discontinue participation at any time. Participation was voluntary, and confidentiality of information and guarantee of anonymity were assured.

\section{Results}

\section{Characteristics of the women interviewed}

A total of 411 women were interviewed with an average age of $49.73( \pm 5.799)$ years, with average time study of 7.72 ( \pm 4.76$)$ years; the average per capita income was $0.739( \pm 0.8111)$ minimum wages; $69.6 \%(n=286)$ reported living with a partner; $51.1 \%$ ( $n=210)$ were white. Regarding way of life, $73.2 \%$ ( $n=301)$ were sedentary and $60.8 \%$ ( $n=245$ ) had a BMl classified as overweight/obese. The presence of at least one condition was reported by $46 \%(n=189)$ (Table 1$)$.

\section{Factors related to complaint of depression in climacteric}

According to the data shown in Table 2, depressive symptoms prevailed in $68.1 \%(n=280)$ of women investigated. In view of this high prevalence, we sought to investigate which factors were related to that event. Therefore the correlation is made between depressive symptoms and variables: sociodemographic, menopausal/postmenopausal and sexual activity, revealing an association with advanced age ( $p=0.009$; OR: 1.693 [Cl 1.113-2.577]), low education ( $p=0.022$; OR: 1.568 [Cl 1.032-2.382]), lower per capita income $(p=0.043$; OR: $1.553[\mathrm{Cl}$ 1.012-2.384]), unpaid labor activity ( $p=0.013$; OR: 1.641 [Cl 1.079-2.495)], menopausal/postmenopausal $[p=0.011$; OR: $1.667(\mathrm{Cl} 1.092-2.545])$, the absence of sexual activity ( $p=0.017$; OR: $1.692[\mathrm{Cl}$ 1.060-2.702]) and sexual activity with a complaint ( $p<0.001$ [OR: 2.777; Cl 1.628-4.737]). Women who were sexually active, but mentioned some pro-
Table 1. Sociodemographic characteristics, lifestyle and morbid frames in climacteric women.

\begin{tabular}{|c|c|c|}
\hline Particularities & n & Results \\
\hline Age $^{*}$ (years) & 411 & $49.73( \pm 5.799)$ \\
\hline Schooling* (years) & 411 & $7.72( \pm 4.76)$ \\
\hline Per capita income* & 411 & $0.739( \pm 0.8111)$ \\
\hline Marital status (fixed companion) & 411 & $69.6 \%(n=286)$ \\
\hline Color of the skin (self-referred) & 411 & $51.1 \%(n=210)$ \\
\hline$<4$ meals/day & 411 & $47.4 \%(n=195)$ \\
\hline Sedentary lifestyle & 411 & $73.2 \%(n=301)$ \\
\hline Smoking & 411 & $21.2 \%(n=87)$ \\
\hline Alcoholism & 411 & $21.9(n=90)$ \\
\hline Overweight/Obesity\# & 403 & $60.8 \%(n=245)$ \\
\hline Diseases $^{+}$ & 411 & $46.0 \%(n=189)$ \\
\hline With hypertension & 411 & $33.8 \%(n=139)$ \\
\hline With diabetes mellitus & 411 & $11.2 \%(n=46)$ \\
\hline \multicolumn{3}{|c|}{$\begin{array}{r}\text { * Average (standard deviation); \# } 8 \text { cases of low weight deleted; } \\
\text { + presence of at least one disease. }\end{array}$} \\
\hline \multicolumn{3}{|c|}{$\begin{array}{l}\text { Source: Research data. Cajazeiras, Paraiba, Brazil; } \\
\text { 2013-2014. }\end{array}$} \\
\hline
\end{tabular}

Table 2. Sociodemographic variables in postmenopausal women and sexual activity versus depressive complaints in climacteric women $(n=411)$.

\begin{tabular}{|c|c|c|c|}
\hline \multicolumn{4}{|c|}{ Depressive complaints } \\
\hline \multirow{2}{*}{ Variables } & $(n=280)$ & $68.1 \%$ & \multirow{2}{*}{ p; OR (CI 95\%) } \\
\hline & $n$ & $\%$ & \\
\hline \multicolumn{4}{|l|}{ Age (years) } \\
\hline $50-60$ & 152 & 54.3 & $0.009 * ; 1.693(1.113-2.577)$ \\
\hline \multicolumn{4}{|c|}{ Schooling (years) } \\
\hline$<8$ & 151 & 53.9 & $0.022 * ; 1.568(1.032-2.382)$ \\
\hline \multicolumn{4}{|c|}{ Per capita income ${ }^{+}$} \\
\hline 0 a 0.74 & 191 & 68.2 & $0.043 * ; 1.553(1.012-2.384)$ \\
\hline \multicolumn{4}{|l|}{ Occupation } \\
\hline Unpaid & 152 & 54.3 & $0.013 * ; 1.641(1.079-2.495)$ \\
\hline \multicolumn{4}{|c|}{ Menopausal State } \\
\hline $\begin{array}{l}\text { Menopause/ } \\
\text { Post } \\
\text { menopause }\end{array}$ & 142 & 50.7 & $0.011 * ; 1.667(1.092-2.545)$ \\
\hline \multicolumn{4}{|c|}{ Sexual activity } \\
\hline No & 99 & 75.6 & $0.017 * ; 1.692(1.060-2.702)$ \\
\hline \multicolumn{4}{|c|}{ Sexual activity } \\
\hline $\begin{array}{l}\text { With } \\
\text { complaint }\end{array}$ & 90 & 49.7 & $<0.001 ; 2.777(1.628-4.737)$ \\
\hline \multicolumn{4}{|c|}{$\begin{array}{r}\text { + Obtained by the sum of family income divided by the number } \\
\text { of family members. }\end{array}$} \\
\hline & $\begin{array}{l}\text { atistical sig } \\
\text { Source: } F\end{array}$ & nificance & $\begin{array}{l}(p<0.05) \text {; * Fisher's Exact Test. } \\
\text { data. Cajazeiras, PB, 2013-2014. }\end{array}$ \\
\hline
\end{tabular}


blem, had almost 3 times (OR: 2.777) the risk of depressive complaint.

\section{Morbid frames and depressive complaints in climacteric}

The data expressed in Table $\mathbf{3}$ show that the presence of depressive symptoms is associated with presence of at least one disease ( $p<0.001 ;$ OR: 2.230 [Cl 1.445-3.440]) and hypertension $(p<0.001 ; \mathrm{OR}$ : 2.276 [Cl 1.412-3.667]).

Table 3. Association between depressive complaints and morbid frames in climacteric women $(n=411)$.

\begin{tabular}{|c|c|c|c|}
\hline \multirow{2}{*}{$\begin{array}{l}\text { Morbid } \\
\text { frames }\end{array}$} & \multicolumn{2}{|c|}{$\begin{array}{l}\text { Depressive } \\
\text { complaints }\end{array}$} & \multirow[t]{2}{*}{ p; OR (CI 95\%) } \\
\hline & $n$ & $\%$ & \\
\hline \multicolumn{4}{|l|}{$\mathrm{BMI}^{+}$} \\
\hline $\begin{array}{l}\text { Overweight/ } \\
\text { obesity }\end{array}$ & 169 & 61.7 & $0.336 ; 1.122(0.732-1.720)$ \\
\hline \multicolumn{4}{|l|}{ Diseases } \\
\hline Yes & 146 & 52.1 & $<0.001 ; 2.230(1.445-3.440)$ \\
\hline \multicolumn{4}{|l|}{ Hypertension } \\
\hline Yes & 110 & 39.3 & $<0.001 ; 2.276(1.412-3.667)$ \\
\hline \multicolumn{4}{|c|}{ Diabetes mellitus } \\
\hline Yes & 31 & 12.1 & $0.555^{*} ; 1.371(0.685-2.742)$ \\
\hline
\end{tabular}

\section{Discussion}

The average age of respondents corresponds to the menopausal transition, marked by variation of the menstrual flow (amenorrhea, polymenorrhea), and was lower than in other population-based studies examining the relationship between menopause and depressive symptoms, [5, 13-14] thus allowing inferences about the early age at which such changes arise in the population studied.

The education level of the participants was considered to be low. However, the result of this research exceeded the average for other studies carried out in Brazil, with climacteric women. $[5,15]$

Regarding the economic status of women, we highlight the low per capita income found, since depressive symptoms occur more frequently among women with low family income, given the economic difficulties and the fact that they are financially dependent on their husband, factors that hinder the marriage and family relationship. In contrast, other research shows that women carrying out paid activity have a 5 times lower risk of developing depression. [7]

Concerning marital status, found a favorable situation because women in stable marital relationships are less likely to develop depressive symptoms. $[5,14]$

In this study, the prevalence of depressive symptoms was high $(68.1 \%)$, surpassing the findings of other studies. $[4,13,15,16]$ This may reflect the economic reality of the studied population. Similarly, the presence of comorbidities and chronic diseases contribute to the outcome of the results. Associated with this, another explanation for this feature could be the fact that women with depressive symptoms make complaints and are less tolerant of menopausal symptoms, often seeking clinical care. [17]

These mood swings can result from many factors: hormonal changes and psychosocial factors in this age group (changes in family structure - a period that coincides with the departure of children from home), retirement, and uncertainty about jobs, marital state and reduced sexual desire and concerns about ageing and body changes. All of these are in addition to the difficulty they have in seeking psychiatric care, psychoemotional disorders that may affect them, sometimes resulting from preconceptions and stigma about the condition itself, or because of the difficulty of access to certain specialties. [18]

The association of depressive symptoms with advancing age is indeed consistent and grounded in the literature. $[14,19]$ Menopause is a period marked by hormonal changes, which result in physical, psychological and social consequences. Therefore, it is a considerably stressful phase, and may lead to changes in mood and even depression. $[15,20]$ 
In this study, we also found an association of depressive symptoms with low schooling, corroborating results of another study, which explained that women with this level of education view it less as a natural process and are more resistant to educational guidelines, leading directly to higher levels of anxiety and depressive symptoms. [5]

Regarding financial conditions, patients with lower per capita income and unpaid occupation showed increased risk for depressive symptoms. In this sense, studies have shown that unemployment is predictive for the development of depressive symptoms. [17, 19]

Studies have reported that low family income can be an important factor in justifying increased rates of depression because it is connected to social conditions such as unemployment, low education, poor quality housing and inadequate food. Such conditions, exclusive or combined, favor the development of a hopeless state, which has the immediate effect of reducing the ability to handle stressful situations properly, reducing willingness to withstand adverse and frustrating events. [21]

The positive correlation between menopause and depressive symptoms was evident. Thus, although it has not been the focus of this investigation, such data infers an important cultural factor associated with sadness/melancholy: the idea that menopause is an end to the personal and professional life of women, which can result in a depressed state. So women, while socio-cultural subjects, have ways of acting, thinking, feeling and interpreting menopause based on their world view. [22]

Analyzing the influence of sexuality on menopausal symptoms, there was a statistically significant association: the fact of presenting sexual activity and no complaints appears to be linked to a decrease in depressive symptoms.

During menopause, most women consider sex to be important, and the main reason for not having sexual activity is the lack of partner, followed by complaints during sex. Thus, we understand the fundamental role of affective fellow look, focused on partnership to secure women's self-image at that age; allowing them to continue to feel sexually desired. $[4,18,23]$

Hypertension was the morbidity that presented as linked to depressive symptoms during menopause. This finding highlights the importance of careful clinical follow-up of hypertensive menopausal women because, among the known risk factors for hypertension, personality traits, the presence of depressive/anxiety symptoms may be important aggravating factors. In contrast, there is epidemiological evidence that a decrease in blood pressure is associated with anxiety and depression. [24, 25]

However, it is difficult to assess the effect of climacteric hormonal variations on blood pressure, since these phenomena are influenced and determined by several factors, such as BMI, socioeconomic status, smoking and lifestyle, among others. [13]

Studies show that individuals with one or more chronic diseases, particularly cardiovascular, had a higher prevalence of depression compared to the general population. [26-27] It is observed that these patients report worse self-assessment of their health, with the greatest number of complaints and greater vulnerability to adverse conditions. [20] In confirming the concurrence of three or more chronic diseases, these individuals were 10 times more likely to have negative perceptions of their health, directly affecting the quality of life in a clear effect number of comorbidities response. [28]

This combination of chronic diseases and depression is related to poor management of comorbidities and consequent poor clinical outcome. A limitation of this study was the impossibility of establishing the chronology of events, due to the cross-sectional design, which did not allow to infer whether women with depressive symptoms have a higher risk of chronic diseases, or due to a greater association of comorbidities, having higher prevalence of these symptoms.

Hormonal, sociocultural factors and comorbidities may act alone or synergistically as triggers of depressive symptoms, especially in postmenopausal 
women. However, the methodology did not allow a cause/effect relationship to be established between variables. It was therefore not possible to determine whether the presence of such factors favors the onset of these symptoms, if they per se attends or provides the appearance of them or both act synergistically favoring or amplifying the symptoms presented.

The limitations of this study add to the failure to identify, for hormonal dosage, the exact period in which the patients were in menopause. Moreover, one cannot disregard the possible presence of thyroid disorders, which would provide an organic cause of depressive symptoms.

Despite those limitations, it is considered that this exploratory study may contribute to the understanding of how these patients proceed through the menopausal transition, helping to facilitate understanding with a clinical and preventive approach, which is revealed as necessary although as yet scarcely available in the locus under study.

\section{Conclusions}

This study points to inferences about the possible correlation between sociodemographic variables, the presence of associated comorbidities and depressive symptoms in climacteric syndrome in patients in primary care. It is also important to note variations in the distribution of depressive complaints in different population groups, to allow better planning, targeted policies, programs and health services for this very particular group of the population.

Depressive complaints are revealed as important adjuncts in the quality of life of women, which may lead to their marginalization from society and health care. Therefore, there is an urgent need for a better primary care structure and a very active and effective public health policy, including specific actions for this population group, so that the index cases are detected and offered treatment for those identified symptoms, in order to minimize the harmful effects that can cause mood changes.

\section{Competing Interests}

The authors have declared that no competing interests exist.

\section{Acknowledgements}

- Renan Alves Silva, Platiny Benício Calou, Helen Melo Oliveira and Danielly Hallany de Bessa Cavalcante - who contributed towards the article by acquisition of data.

- All authors with own resources developed this research.

\section{References}

1. De Lorenzi DRS, Catan LB, Moreira K, Ártico GR. Assistance to the climacteric woman: new paradigms. Rev Bras Enferm [Internet] 2009 Apr; 62(2): 287-293. doi: http://dx.doi. org/10.1590/S0034-71672009000200019.

2. IBGE. Instituto Brasileiro de Geografia e Estatística. Expectativa de vida ao nascer, 2013. http://saladeimprensa.ibge.gov.br/noti cias? view $=$ noticia\&id $=1 \&$ busca $=1$ \&idnoticia $=2773$. Accessed 26 Dec 2014.

3. Ministério da Saúde (BR). Secretaria de Atenção à Saúde. Manual de Atenção à Mulher no Climatério/Menopausa. Brasília: Ministério da Saúde; 2008. bvsms.saude.gov.br/.../manual_ atencao_mulher_climaterio.pdf. Accessed 02 Feb 2015.

4. Galvão LLLF, Farias MCS, Azevedo PRM, Vilar MJP, Azevedo GD. Prevalence of mental disorders and assessment of quality of life in the climaterium. Rev Assoc Med Bras São Paulo 2007 sept/oct; 53(5): 414-20. doi: http://dx.doi.org/10.1590/S010442302007000500017

5. De Lorenzi DRS, Danelon C, Saciloto B, Padilha Jr I. Predicting factors of climacteric symptoms. Rev Bras Ginecol Obstet 2005 jan; 27(1): 7-11. doi: http://dx.doi.org/10.1590/S0100$\underline{72032005000100004}$

6. Berlezi EM, Balzan A, Cadore BF, Pillatt AP, Winkelmann ER. Histórico de transtornos disfóricos no período reprodutivo e a associação com sintomas sugestivos de depressão na pósmenopausa. Revista Brasileira de geriatria e gerontologia [Internet] 2013; 16(2): 273-83. doi: http://dx.doi.org/10.1590/ $\underline{\mathrm{S} 1809-98232013000200007}$

7. Polisseni ÁF, Araújo DAC, Polisseni F, Mourão Junior CA, Polisseni J, Fernandes ES, et al. Depressão e ansiedade em mulheres climatéricas: fatores associados. Rev Bras Ginecol Obstet 2009 mar; 31(1): 28-34. doi: http://dx.doi.org/10.1590/ $\underline{\mathrm{S} 0100-72032009000300003}$

8. Niedhammer I, Malard L, Chastang J-F. Occupational factors and subsequent major depressive and generalized anxiety disorders in the prospective French national SIP study. BMC Public Health 2015; 15: 200 http://www.biomedcentral.com/14712458/15/200 doi: 10, 1186/s12889-015-1559-y. 
9. IBGE. Instituto Brasileiro de Geografia e Estatística. IBGE cidades@. Cajazeiras - PB: dados básicos. http://www.ibge.gov. br/cidadesat/painel/painel.php?codmun=250370. Accessed 12 Jan 2015.

10. Stefanis CN, Stefanis NC. Diagnóstico de Desordens depressiva: uma revisão. In: M Maj \& N Sartorius (Orgs.). Desordens depressiva. Porto Alegre: Editora Artes Médicas, 2005: 13-76.

11. Wender COM, Freitas F, De Castro JAS, Vanin C. Climatério. In: Freitas F, Menke CH, Rivoire WA, Passos EP. Rotinas em ginecologia. Porto Alegre: Artmed; 2011: 542-60.

12. Jardim S. Depressão e trabalho: ruptura de laço social. Revista Brasileira de Saúde Ocupacional São Paulo 2011 jan/june; 36(123): 84-92. http://www.scielo.br/scielo.php?script=sci arttext\&pid=S0303-76572011000100008\&lng=en\&nrm=iso. Accessed 21 Nov 2014.

13. Berni NIO, Luz MH, Kohlrausch SC. Conhecimento, percepções e assistência à saúde da mulher no climatério. Rev Bras Enferm [Internet] Brasília 2007 may/june; 60(3): 299-306. doi: http://dx.doi.org/10.1590/s0034-71672007000300010.

14. Silva MNM, Brito LMO, Chein MBC, Brito LGO, Navarro PAAS. Depressão em mulheres climatéricas: análise de mulheres atendidas ambulatorialmente em um hospital universitário no Maranhão, Brasil. Revista de psiquiatria do Rio Grande o Sul Porto Alegre 2008 may/aug; 30(2): 150-4. doi: http://dx.doi.org/10.1590/S0101-81082008000300011.

15. Nievas $A F$, Furegato ARF, lannetta $O$, Santos JLF. Depressão no climatério: indicadores biopsicossociais. I bras psiquiatr [Internet] Rio de Janeiro 2006; 55(4): 274-9. doi: http://dx.doi. org/10.1590/S0047-20852006000400003.

16. Fernandes RCL, Rozenthal M. Depressive symptoms in climacteric women evaluated by the Center for Epidemiological Studies Depression Scale. Revista de psiquiatria do Rio Grande do Sul Porto Alegre 2008 sept/dec; 30(3): 192-200. doi: http://dx.doi.org/10.1590/S0101-81082008000400008.

17. Cohen LS, Soares CN, Vitones AF, Otto MW, Harlow BL. Risk for new onset of depression during the menopausal transition: the Harvard study of moods and cycles. Arch Gen Psychiatry Boston 2006 apr; 63(4):385-90. doi:10.1001/archpsyc.63.4.385.

18. Martins RV, Barreto JM. Depression in middle-aged women. In: II Nacional Gênero e Práticas Culturais: cultras, leituras e representações. 29-30 outubro 2009; João Pessoa. João Pessoa: Centro de Educação, UFPB PB; 2009. p. 1-9. http://itaporanga. net/genero/gt6/22.pdf. Accessed 12 Dec 2014.

19. Veras $A B$, Rassi $A$, Yukizaki LMG, Novo LD, Franco FS, Nardi AE. Impacto dos transtornos depressivos e ansiosos sobre as manifestações da menopausa. Revista de psiquiatria do Rio Grande do Sul Porto Alegre 2007 dec; 29(3): 315-20. doi: http://dx.doi.org/10.1590/S0101-81082007000300011.

20. Alves LC, Rodrigues RN. Determinants of self-rated health among elderly persons in São Paulo, Brazil. Rev Panam Salud Publica 2005 may-jun; 17(5-6): 333-41. doi: 10.1590/S102049892005000500005 PMCID: PMC16053643

21. Mello MF, Mello AAF, Kohn R. Epidemiologia da saúde mental no Brasil. Porto Alegre: Artmed; 2007.

22. Costa GMC, Gualda DMR. Conhecimento e significado cultural da menopausa para um grupo de mulheres. Rev Esc Enferm USP [Internet] 2008 mar; 42(1): 81-9. doi: http://dx.doi.org/10.1590/ S0080-62342008000100011.
23. Poli MEH, Schwanke CHA, Cruz IBM. The menopause in the gerontologic view. Sci Med (Porto Alegre) 2010 apr/june; 20(2), 176-84. Available from: http://revistaseletronicas.pucrs.br/ojs/ index.php/scientiamedica/article/view/5893/5428. Accessed 14 Nov 2014

24. Hildrum B, Mykletun A, Stordal E, Bjelland I, Dahl AA, Holmen J. Association of low blood pressure with anxiety and depression: the Nord-Trondelag Health Study. I Epidemiol Community Health 2007; 61: 53-8. doi:10.1136/jech.2005.044966

25. Hildrum B, Homild U, Holmen J. Anxiety and depression lowers blood pressure: 22-year follow-up of the population based HUNT study, Norway. BMC Public Health 2011; 11: 601. Publicado online 28 de julho 2011 doi: 10.1186/1471-2458-11-601

26. Blumenthal JA, Newman M, Babyak MA, Lett HS, Mark D. Depression as a risk factor for mortality after coronary artery bypass surgery. Lancet 2003 nov; 362(9384): 604-9. doi: http:// dx.doi.org/10.1016/S0140-6736(03)14704-6

27. WJ Katon. Epidemiology and treatment of depression in patients with chronic medical illness. Dialogues Clin Neurosci 2011; 13(1): 7-23. PMCID: PMC3181964

28. Wang HM, Beyer M, Gensichen J, Gerlach FM. Health-related quality of life among general practice patients with differing chronic diseases in Germany: cross sectional survey. BMC Public Health. Germany 2008; 8: 246. doi:10.1186/1471-2458-8-246

\section{Comment on this article:}

\section{$9 \mathbb{B}$ in $8+\boldsymbol{S} P$}

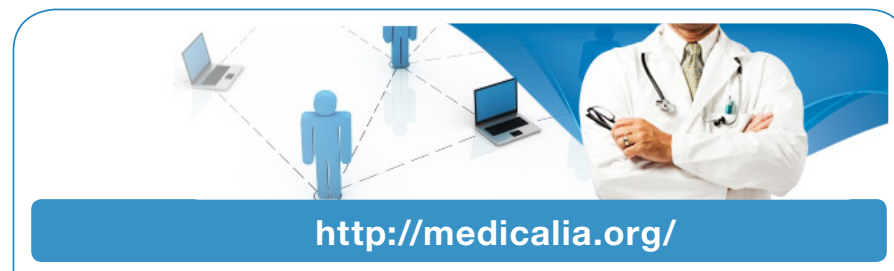

Where Doctors exchange clinical experiences, review their cases and share clinical knowledge. You can also access lots of medical publications for free. Join Now!

\section{Publish with iMedPub}

http://www.imed.pub

International Archives of Medicine is an open access journal publishing articles encompassing all aspects of medical science and clinical practice. IAM is considered a megajournal with independent sections on all areas of medicine. IAM is a really international journal with authors and board members from all around the world. The journal is widely indexed and classified Q1 in category Medicine. 